\title{
OPTIMASI MODEL IDENTIFIKASI BAHAN BAKAR MINYAK MELALUI PEMILIHAN FITUR
}

\author{
Dini Fakta Sari \\ STMIK AKAKOM Yogyakarta \\ Jl. Raya Janti 143, Yogyakarta. \\ dini@akakom.ac.id
}

\begin{abstract}
Abstrak
Bahan Bakar Minyak (BBM) sangat penting dalam semua aktifitas ekonomi khususnya sebagai bahan bakar kendaraan bermotor. Jumlah kendaraan bermotor tiap tahunnya mengalami peningkatan sehingga mempengaruhi ketersediaan BBM. Pencampuran BBM akan mempengaruhi performa mesin kendaraan bermotor sehingga masyarakat harus mampu mengenali BBM yang berkualitas salah satunya dari bau BBM itu sendiri.
\end{abstract}

Penelitian ini, melanjutkan dari penelitian sebelumnya tentang sistem identifikasi odor/bau yang memiliki kekurangan yakni proses pembelajaran yang lama dan data uji seperti amoniak, alkohol dan minyak tanah. Optimasi model identifikasi BBM yang akan dibangun menggunakan algoritma Back Propagation Neuron Networks sebagai model pembelajaran dan Principle Component Analysis sebagai metode pemilihan fitur. BBM yang dijadikan data uji antara lain bensin, pertamax dan kerosin.

Penelitian ini menghasilkan model yang mampu mengidentifikasi BBM yang diujikan dengan optimasi model melalui pemilihan fitur dengan nilai akurasi sebesar 93\%.

kata kunci : Bahan Bakar Minyak, Principle Component Analysis, Back Propagation Neuron Networks.

\section{Pendahuluan}

Bahan Bakar Minyak (BBM) merupakan komoditas yang memegang peranan sangat penting dalam semua aktifitas ekonomi khususnya sebagai bahan bakar kendaraan bermotor. Seiring dengan perkembangan teknologi pada dunia otomotif, terjadi peningkatan jumlah kendaraan bermotor tiap tahunnya sehingga ketersediaan BBM oleh pemerintah sangat berpengaruh. Permasalahan yang dapat muncul dari ketersediaan BBM yaitu sering terjadinya kelangkaan BBM di beberapa daerah, munculnya pangkalan pengisian BBM yang tidak resmi, penimbunan BBM dan pencampuran BBM dengan bahan yang dapat menyebabkan penurunan kualitas oleh oknum yang tidak bertanggung jawab. Berdasarkan permasalahan tersebut, masyarakat harus mampu mengenali BBM yang berkualitas salah satunya dari bau BBM itu sendiri.

Analisis kualitatif dan kuantitatif komposisi BBM dapat dilakukan dengan metode kromatografi gas. Permasalahannya adalah instrumen kromatografi gas tidak portabel dan biaya perawatan dan operasionalnya mahal. Implementasi artificial neural network pada Field Programmable Gate Array (FPGA) dalam sistem identifikasi odor [1]. Sistem gugusan sensor gas yang dikembangkan dapat mengidentifikasi jenis odor yang diujikan namun masih terdapat beberapa kelemahan yaitu waktu pembelajaran yang lama dan odor yang diujikan memiliki perbedaan bau yang sangat menyengat seperti amoniak, alkohol, dan minyak tanah. Penelitian ini merupakan lanjutan dari penelitian sebelumnya yakni optimasi model identifikasi dengan menggunakan Back Propagation Neuron Networks sebagai model pembelajaran dan Principle Component Analysis sebagai pemilihan fitur pada ujicoba odor seperti bensin, pertamax dan kerosin.

Metoda Principle Component Analysis (PCA) sering digunakan untuk visualisasi hasil klasifikasi pada sistem identifikasi. PCA juga mampu memproyeksikan data sepanjang suatu arah dimana data tersebut memiliki varians yang tinggi. Pengujian pengaruh Principle Component Analysis terhadap tingkat identifikasi neural network pada sistem sensor gas [2]. Pengaruh yang dihasilkan yaitu dapat meningkatkan performa yang meliputi taraf identifikasi dan waktu yang diperlukan dalam fase pelatihan. Penggunaan metode PCA pada penelitian ini ditujukan untuk mengurangi dimensi data dengan mempertahankan sebanyak mungkin informasi dari dataset yang asli dari data Bahan Bakar Minyak yang dijadikan sebagai data uji.

Klasifikasi merupakan proses untuk menemukan sekumpulan model yang menjelaskan dan membedakan kelas-kelas data, sehingga model tersebut dapat digunakan untuk memprediksi nilai suatu kelas yang belum diketahui pada sebuah objek [3]. Untuk mendapatkan model, dilakukan analisis terhadap data latih (training set). Data uji (test set) 
digunakan untuk mengetahui tingkat akurasi dari model yang telah dihasilkan. Algoritma Back Propagation Neuron Networks merupakan algoritma pada artificial neural network dengan pembelajaran terawasi [4].

\section{Diskusi}

Bensin dan kerosin merupakan produk minyak bumi hasil proses distilasi. Dalam minyak bumi terdapat senyawa selain hidrokarbon yaitu senyawa organik yang mengandung belerang, oksigen, dan logam-logam. Pencampuran premium dengan kerosin dapat meningkatkan senyawasenyawa belerang yang mengakibatkan beberapa kerugian sebagai bahan bakar motor seperti pembakaran membentuk Nitrogen Oksida (NOx) dan Sulfur Oksida (SOx). Penyebab tingginya pencemaran gas NOx dari knalpot kendaraan bermotor ialah karena tidak sempurnanya pembakaran BBM dalam ruang bakar mesin, di mana pembentukan NOx dipengaruhi oleh suhu pembakaran yang tinggi dan kelebihan udara yang tersedia. Adanya suhu tinggi reaksi pembakaran yang terjadi selalu disertai pembentukan gas-gas lain seperti gas SOx. Kandungan gas SOx sebanding dengan semakin besarnya jumlah kerosin yang diberikan. Kandungan gas NOx sesuai dengan penambahan perbandingan premium dan kerosin yang diberikan [5].

Alat identifikasi odor secara umum terdiri dari sensor resonator kuarsa, signal conditioning, FPGA dan display. Sensor resonator kuarsa yang digunakan ada 3 buah, masing-masing sensor dihubungkan ke rangkaian osilator dan mixer. Frekuensi yang keluar dari rangkaian mixer akan menjadi data masukan ke FPGA. Pada FPGA terdapat beberapa proses yang terdiri dari frekuensi counter, pewaktu 1 detik, latch, multiplexer, program untuk serial interface, program pengujian artificial neural network dan program untuk LCD. Pembacaan frekuensi untuk masing-masing sensor ditampilkan pada komputer. Proses pembelajaran dari artificial neural network dengan model Multi Layer Perceptron dengan metode pelatihan Back Propagation dilakukan di komputer sedangkan proses pengujian artificial neural network dilakukan di FPGA yang hasilnya akan ditampilkan pada LCD yang terdapat pada board FPGA [1].

Metoda Principle Component Analysis (PCA) sering digunakan untuk visualisasi hasil klasifikasi pada sistim identifikasi. Metoda ini merupakan penurunan dari teknik factor analysis yang bertujuan untuk mengidentifikasi struktur dari banyak variable menjadi data yang lebih sederhana. Metoda ini juga dikenal sebagai transfomasi Karhunen-Loève atau transformasi Hotelling. PCA merupakan transformasi linier ortogonal yang mentransformasi data ke dalam koordinat sistem yang baru yang mana variasi yang paling banyak diperoleh dari proyeksi data pada koordinat prioritas utama (principle component) yang pertama, variasi kedua yang terbanyak pada koordinat prioritas utama yang kedua dan seterusnya. PCA biasanya digunakan untuk mengurangi dimensi dari himpunan data tetapi juga mempertahankan karakteristik dari himpunan data tersebut dengan menjaga beberapa principle component yang tinggi prioritasnya dan membuang beberapa principle component yang rendah prioritasnya [2].

Ada beberapa metoda yang umum digunakan untuk mendapatkan principle component pada metoda PCA, yaitu metoda covariance, metoda korelasi dan singular value decomposition. Prosedur PCA dengan menggunakan metoda covariance [2] adalah sebagai berikut:

1. Menghimpun data eksperimen $X(M, N)$ yang memiliki dimensi tertentu yang berkesesuaian dengan variabel atau jumlah sensor yang digunakan (M) dan jumlah data $(\mathrm{N})$.

2. Mengurangkan setiap data $X$ dengan nilai mean mXuntuk masing-masing variable atau sensor $(m)$.

$$
\begin{aligned}
& \bar{X}_{m}=\frac{1}{N} \sum_{n=1}^{N} X(M, n) \\
& X=X-\bar{X}_{m}
\end{aligned}
$$

3. Mendapatkan matriks covariance (C)

$$
\operatorname{cov}\left(\mathrm{X}_{1}, \mathrm{X}_{2}\right)=\frac{\sum_{\mathrm{n}=1}^{\mathrm{N}}\left(\mathrm{x}_{1}-\overline{\mathrm{X}}_{1}\right)\left(\mathrm{x}_{2}-\overline{\mathrm{X}}_{2}\right)}{(\mathrm{N}-1)}
$$

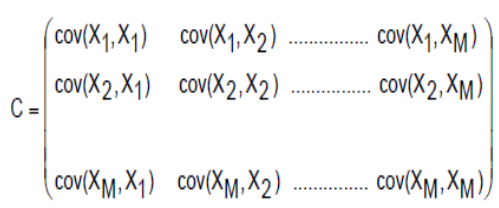

4. Mendapatkan eigenvalue $(\lambda)$ dan eigenvector $(\mathrm{V})$ dari matrik covariance

$$
(\mathrm{C}-\lambda) \mathrm{V}=\mathrm{O}
$$

Teknik untuk mendapatkan eigenvalue dan eigenvector ini dapat digunakan beberapa metoda yaitu power method, orthogonal iteration, QL method, Lanczos method, dan Jacobi's method. 
5. Mendapatkan principle component (PC)

$$
\mathrm{PC}_{\mathrm{i}}=\mathrm{x} \cdot \mathrm{V}_{\mathrm{i}}^{\mathrm{T}}
$$

dengan $\mathrm{PC}_{1}$ adalah principle component pertama, $V_{1}$ eigenvector dengan nilai eigenvalue terbesar.

Artificial Neural Network adalah paradigma pemrosesan informasi yang terinspirasi dengan cara biologi pada sistem saraf, seperti otak. IImuwan mencoba untuk meniru otak dengan kemampuan artificial neural network. Algoritma Back propagation paling banyak digunakan untuk algoritma pelatihan multi-layered feedforward neuron networks Standar back propagation membutuhkan waktu untuk menyesuaikan dengan bobot antara unit-unit dalam jaringan untuk meminimalkan Mean Square Errors (MSE) antara output yang diinginkan dan output yang sebenarnya [6].

Algoritma pelatihan untuk jaring dengan satu lapis tersembunyi [1] menggunakan fungsi aktivasi tansig adalah sebagai berikut :

1. Inisialisasi semua bobot dengan bilangan acak kecil

2. Jika kondisi penghentian belum terpenuhi, lakukan langkah 3-9.

3. Untuk setiap pasang data pelatihan, lakukan langkah 4-9.

Tahap pertama : propagasi maju

4. Tiap unit masukan menerima sinyal dan meneruskannya ke unit tersembunyi diatasnya.

5. Hitung semua keluaran di unit tersembunyi $z_{j}$ $(j=1,2, . . p)$

$$
\begin{aligned}
& z_{-} n e t_{j}=v_{0 j}+\sum_{i=1}^{n} x_{i} v_{i j} \quad \text { (pers. 7) } \\
& z_{j}=f_{1}\left(z_{-} n e t_{j}\right)=\frac{e^{z_{-} n e t}-e^{-z_{-} n e t}}{e^{z_{-} n e t}+e^{-z_{-} n e t}} \text { (pers8) }
\end{aligned}
$$

6. Hitung semua keluaran jaring di semua unit $y_{k}$ $(\mathrm{k}=1,2, . ., \mathrm{m})$

$$
\begin{array}{ll}
y_{-} n e t_{k}=w_{0 k}+\sum_{j=1}^{p} z_{j} \cdot w_{j k} & \text { (pers. 9) } \\
y_{k}=f_{2}\left(y_{-} n e t_{k}\right)=\frac{e^{y_{-} n e t}-e^{-y_{-} n e t}}{e^{y_{-} n e t}+e^{-y_{-} n e t}} \quad \text { (pers.10) }
\end{array}
$$

7. Hitung faktor $\delta$ unit keluaran berdasarkan kesalahan di setiap unit keluaran $y_{k}$ $(\mathrm{k}=1,2, \ldots, \mathrm{m})$

$\delta_{k}=\left(t_{k}-y_{k}\right) f^{\prime}\left(y_{-} n e t_{k}\right)=\left(t_{k}-y_{k}\right) \cdot y_{k} \cdot\left(1-y_{k}\right)$

$\delta_{k}$ merupakan unit kesalahan yang akan dipakai dalam perubahan bobot lapis dibawahnya (langkah 8)

Hitung suku perubahan bobot $w_{j k}$ (yang akan dipakai nanti untuk merubah bobot $W_{j k}$ ) dengan laju percepatan.

$$
\Delta w_{j k}=\alpha \delta_{k} z_{j} \quad ; \mathrm{k}=1,2, \ldots, \mathrm{m} ; \mathrm{j}=0,1, \ldots, \mathrm{p} .
$$

(pers.12)

8. Hitung faktor $\delta$ unit tersembunyi berdasarkan kesalahan di setiap unit tersembunyi $z_{j}$ $(j=1,2, \ldots, p)$

$\delta_{-} n e t_{j}=\sum_{k=1}^{m} \delta_{k} \cdot w_{j k}$

(pers.13)

Faktor $\delta$ unit tersembunyi :

$\delta_{j}=\delta_{-} n e t_{j} f^{\prime}\left(z_{-} n e t_{j}\right)=\delta_{-} n e t_{j} z_{j}\left(1-z_{j}\right)$

Hitung suku perubahan bobot $\mathrm{v}_{\mathrm{ji}}$ (yang akan dipakai nanti untuk merubah bobot $\mathrm{v}_{\mathrm{ji}}$ )

$$
\Delta v_{i j}=\alpha \delta_{j} x_{i} \quad ; \quad \mathrm{j}=1,2, \ldots, \mathrm{p} ; \quad \mathrm{i}=0,1, \ldots, \mathrm{n}
$$

(pers..15)

Tahap ketiga : perubahan bobot

9. Hitung semua perubahan bobot

Perubahan bobot garis yang menuju ke unit keluaran :

$w_{j k}($ baru $)=w_{j k}($ lama $)+\Delta w_{j k}$

$(k=1,2, \ldots, m ; j=0,1, \ldots, p)$.

(pers.16)

Perubahan bobot garis yang menuju ke unit tersembunyi :

$$
\begin{gathered}
v_{i j}(\text { baru })=v_{i j}(\operatorname{lama})+\Delta v_{i j} \\
(\mathrm{j}=1,2, \ldots, \mathrm{p} ; \mathrm{i}=0,1, \ldots, \mathrm{n}) .
\end{gathered}
$$

Setelah pelatihan selesai dilakukan, jaring dapat dipakai untuk pengenalan pola. Dalam hal ini, hanya propagasi maju (langkah 5 dan 6) saja yang dipakai untuk menentukan keluaran ANN.

Tahapan-tahapan dalam menentukan ekstarksi ciri/fitur menggunakan Principle Component Analysis dari Bahan Bakar Minyak dapat dilihat pada gambar hasil eksperimen di olah untuk mendapatkan nilai mean dari masingmasing variabel data tersebut, kemudian mencari nilai covarian dengan menggunakan rumus matrik covarian yang nantinya hasilnya akan digunakan untuk mencari nilai eigenvalue dan eigenvector, sehingga principle component dari data eksperiman dapat diperoleh. 


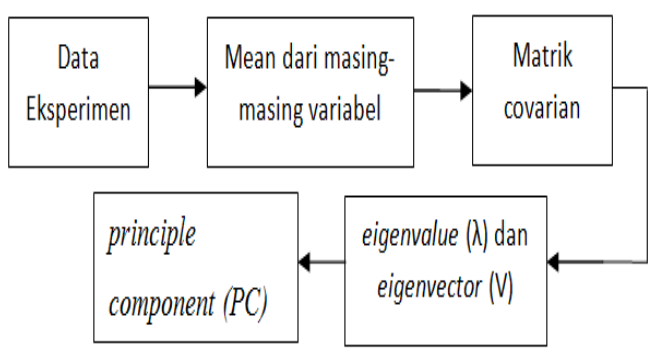

Gambar . Tahapan Principle Component Analysis

Perancangan Back Propagation Neural Network dapat dilihat pada gambar. Proses Back Propagation Neural Network dibagi menjadi dua proses yaitu proses pembelajaran dan proses pengujian. Data hasil ekstraksi ciri Bahan Bakar Minyak akan dijadikan input pada proses pembelajaran ANN untuk mendapatkan bobotbobot pembelajaran. Bobot-bobot akan terus diperbaharui sampai epoch yang ditentukan. Bobot-bobot yang didapatkan pada proses pembelajaran akan dipergunakan pada komputasi proses pengujian artificial neural network sehingga didapatkan hasil klasifikasi Bahan Bakar Minyak.

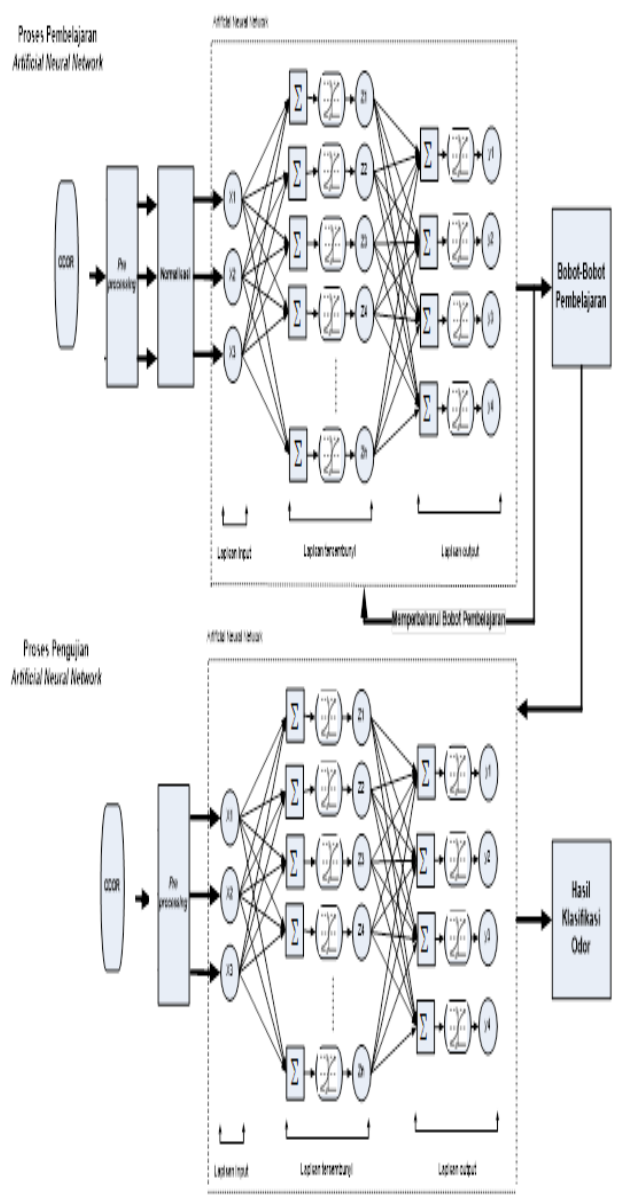

Gambar Perancangan Back Propagation Neural Network
Hasil penelitian dengan pengambilan data uji menggunakan sensor resonator kuarsa dengan polimer cellulose, OV-275, dan PEG 1540 pada alat identifikasi odor dari hasil penelitian sebelumnya, dimana data yang akan dihasilkan akan di ekstraksi menggunakan principle component analysis untuk mendapatkan data set, yang nantinya akan digunakan untuk mengetahui seberapa optimal pengenalan polanya.

Hasil pengenalan pola menggunakan Back Propagation Neural Network dengan data input dari hasil ekstraksi ciri :

\begin{tabular}{|c|c|c|c|c|c|c|}
\hline \multirow{2}{*}{ Pengujian } & \multirow{2}{*}{ Epoch } & \multirow{2}{*}{ MSE } & \multicolumn{3}{|c|}{ Output Neuron (Pengujian) } & \multirow{2}{*}{$\begin{array}{c}\text { Tingkat } \\
\text { Akurasi } \\
\text { Pengujian (\%) }\end{array}$} \\
\hline & & & Bensin & Minyak Tanah & Pertamax & \\
\hline 1 & 20 & 1.186 & 0.499181 & 0.834532 & 0.532499 & 76 \\
\hline 2 & 40 & 1.188 & 0.403835 & 0.830431 & 0.512943 & 76 \\
\hline 3 & 60 & 1.079 & 0.736469 & 0.675181 & 0.51701 & 77 \\
\hline 4 & 80 & 0.998 & 0.361191 & 0.943818 & 0.484691 & 85 \\
\hline 5 & 100 & 0.047 & 0.326097 & 0.797156 & 0.480419 & 93 \\
\hline 6 & 120 & 0.047 & 0.888167 & 0.742053 & 0.475366 & 93 \\
\hline 7 & 140 & 0.047 & 0.516244 & 0.679979 & 0.496882 & 93 \\
\hline 8 & 160 & 0.047 & 0.510995 & 0.769231 & 0.507575 & 93 \\
\hline 9 & 180 & 0.047 & 0.403684 & 0.764006 & 0.452895 & 93 \\
\hline 10 & 200 & 0.047 & 0.210264 & 0.580951 & 0.498558 & 93 \\
\hline
\end{tabular}

Hasil pengenalan pola menggunakan Back Propagation Neural Network tanpa ekstraksi ciri :

\begin{tabular}{|c|c|c|c|c|c|c|}
\hline \multirow{2}{*}{ Pengujian } & \multirow{2}{*}{ Epoch } & \multirow{2}{*}{ MSE } & \multicolumn{3}{|c|}{ Output Neuron (Pengujian) } & $\begin{array}{c}\text { Tingkat } \\
\text { Akurasi } \\
\text { Pengujian (\%) }\end{array}$ \\
\cline { 4 - 6 } & & & Bensin & Minyak Tanah & Pertamax & \\
\hline 1 & 20 & 1.989 & 0.625341 & 0.459563 & 0.412678 & 70 \\
\hline 2 & 40 & 1.689 & 0.625358 & 0.417201 & 0.398812 & 71 \\
\hline 3 & 60 & 1.728 & 0.472938 & 0.39158 & 0.383604 & 70 \\
\hline 4 & 80 & 1.897 & 0.677798 & 0.408038 & 0.380871 & 70 \\
\hline 5 & 100 & 1.987 & 0.664946 & 0.386609 & 0.369523 & 70 \\
\hline 6 & 120 & 1.683 & 0.650903 & 0.384923 & 0.369563 & 70 \\
\hline 7 & 140 & 1.332 & 0.622157 & 0.359247 & 0.362436 & 86 \\
\hline 8 & 160 & 0.987 & 0.706108 & 0.345438 & 0.369619 & 89 \\
\hline 9 & 180 & 0.987 & 0.910292 & 0.335435 & 0.361711 & 89 \\
\hline 10 & 200 & 0.987 & 0.69779 & 0.295777 & 0.356313 & 89 \\
\hline & & & & & & \\
\hline & & & & & & \\
\hline & & & & & & \\
\hline
\end{tabular}


Berdasarkan hasil percobaan pada penelitian "Optimasi Model Identifikasi Bahan Bakar Minyak Melalui Pemilihan Fitur", diperoleh nilai akurasi dalam mengidentifikasi bahan bakar minyak yang diujikan dapat dilihat pada gambar 4.4.. Model identifikasi bahan bakar minyak dengan pemilihan fiture memiliki nilai akurasi dalam mengidentifikasi bahan yang diujikan sebesar 93\% sedangkan model identifikasi bahan bakar minyak tanpa pemilihan fiture memiliki nilai akurasi dalam mengidentifikasi bahan yang diujikan sebesar $83 \%$.

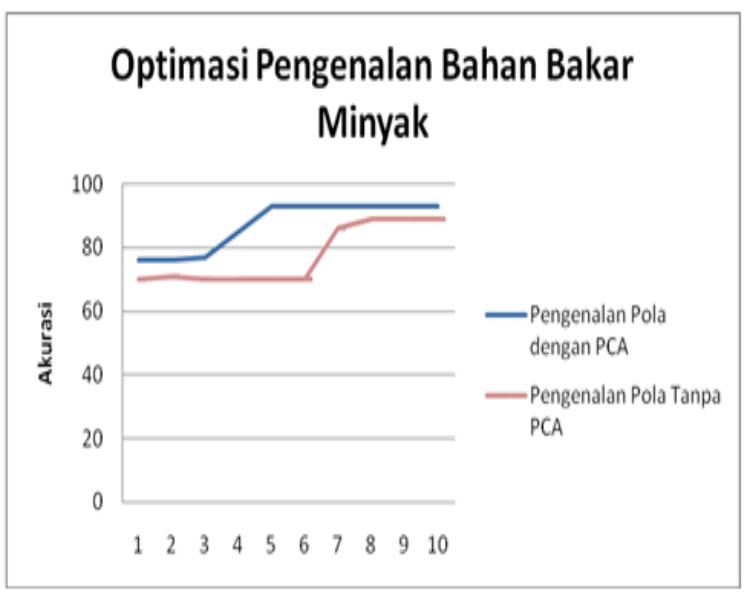

\section{Kesimpulan}

Kesimpulan hasil penelitian mengenai "Optimasi Model Identifikasi Bahan Bakar Minyak Melalui Pemilihan Fitur" sebagai berikut :

1. Bensin, Minyak tanah dan pertamax yang termasuk dalam Bahan Bakar Minyak, bila diidentifikasi menggunakan sistem penciuman manusia memiliki bau yang hamper sama sehingga untuk mengetahui secara akurat perbedaan odor dari bahan yang diujikan, diperlukan alat identifikasi odor.

2. Model yang diterapkan pada alat identifikasi odor dalam melakukan identifikasi bahan yang diujikan dengan menggunakan metode Back Prpagation Neural Network.

3. Model identifikasi bahan bakar minyak dengan menggunakan metode Back Prpagation Neural Network. dan pemilihan fiture pada proses pre processing memiliki nilai akurasi dalam mengidentifikasi bahan yang diujikan sebesar $93 \%$.

4. Model identifikasi bahan bakar minyak dengan menggunakan metode Back
Prpagation Neural Network tanpa pemilihan fiture pada proses pre processing memiliki nilai akurasi dalam mengidentifikasi bahan yang diujikan sebesar $83 \%$.

5. Berdasarkan kedua model yang dibangun, maka dapat disimpulkan bahwa model identifikasi Bahan Bakar Minyak melalui pemilihan fitur lebih optimal di bandingkan model identifikasi Bahan Bakar Minyak tanpa pemilihan fitur.

\section{Daftar Pustaka}

[1] Sari, DF., Rivai, M., Mujiono, T., 2010, "Implementasi Artificial Neural Network Pada Field Programmable Gate Array (FPGA) Dalam Sistem Identifikasi Odor", Tesis, Program Master, Teknik Elektro, ITS, Surabaya.

[2] Rivai Muhammad, 2007,"Pengaruh Principle Component Analysis Terhadap Tingkat Identifikasi Neural Network Pada Sistem Sensor gas" TELKOMNIKA Vol.5, No.3, Desember 2007 : 159 - 167. ISSN :1693-6930.

[3] Ismaya, Agny, 2005, " Analisis Dan Implementasi Optimal Brain Surgeon (OBS) Untuk Klasifikasi Pada Data Mining", Tugas Akhir, Jurusan Teknik Informatika, STT TELKOM, Bandung.

[4] Misbah, 2009," Implementasi FPGA sebagai Digital Interface Pada Sensor Gas Resonator Kuarsa Untuk Mendeteksi Amoniak", Tesis, Program Master, Teknik Elektro, ITS, Surabaya.

[5] Dewi, YS. dan Budiyanti, T., 2010," Pengaruh Campuran Kadar Kerosin Dalam Premium Terhadap Emisi Gas Sulfur Oksida Dan Nitrogen Oksida Pada Kendaraan Bermotor", Jurnal Limit's, FT,Universitas Satya Negara Indonesia, Volume 6 No.2 September 2010, ISSN 0216-1184.

[6] Medhat Moussa, 2006," On The Arithmetic Precision For Implementing Backpropagation Networks On FPGA : A Case Study", A C.I.P. Canada. 